\title{
Music's effect on pain relief during outpatient urological procedures: a single center, randomized control trial focusing on gender differences
}

\author{
Christopher Anglin ${ }^{1}$, Paul Knoll ${ }^{2}$, Brandon Mudd ${ }^{1}$, Craig Ziegler ${ }^{3}$, Kellen Choi $^{2}$ \\ ${ }^{1}$ University of Louisville School of Medicine, Louisville, Kentucky, USA; ${ }^{2}$ Department of Urology, University of Louisville Hospital, Louisville, \\ Kentucky, USA; ${ }^{3}$ University of Louisville School of Medicine Office of Undergraduate and Graduate Medical Education, Louisville, Kentucky, USA \\ Contributions: (I) Conception and design: P Knoll, K Choi; (II) Administrative support: K Choi; (III) Provision of study materials or patients: K Choi; \\ (IV) Collection and assembly of data: K Choi, P Knoll, B Mudd; (V) Data analysis and interpretation: C Ziegler, C Anglin; (VI) Manuscript writing: \\ All authors; (VII) Final approval of manuscript: All authors. \\ Correspondence to: Kellen Choi, DO, FACOS. Department of Urology, University of Louisville Hospital, 401 E Chestnut St, Ste 510, Louisville, KY, \\ 40202, USA. Email: Kellen.choi@ulp.org.
}

Background: Listening to preferred music can provide distraction and reduce the feeling of pain and negative emotions associated with an uncomfortable experience. Several studies have examined how music can reduce pain and anxiety related to urological procedures that are not typically performed under anesthesia, such as cystoscopy, cystoscopy with stent pull, and urodynamic studies. To our knowledge, no studies have been done to examine the effect of listening to preferred music generalized across a variety of these procedures. Therefore, we looked to combine multiple factors from prior studies to determine if listening to music of a patient's choice would decrease pain during various outpatient clinic urological procedures, and to examine differences between men and women.

Methods: This was a single investigator series randomized controlled trial with 91 subjects in an academic outpatient urology clinic. After applying exclusion criteria, eligible patients were randomized to a music group or non-music group via coin flip. Fifty-three patients were in the music group (16 men, 37 women) and 38 patients were in the non-music group (16 men, 22 women). Subjects in the music group selected a song to play during the procedure, which was stopped at the conclusion of the procedure. Pre- and postprocedure Visual Analog Pain Scale were completed by the subjects of each group and subsequently analyzed. Where appropriate either Pearson's Chi-Square or Independent-Sample $t$-test were used to compare the groups as well as randomized-repeated analysis of variance (ANOVA).

Results: For men, pain scores worsened in both groups, however the music group experienced a statistically significant increase in pain (mean change $=1.0, \mathrm{P}=0.05$ ), while the non-music group only clinically worsened (mean change $=0.38, \mathrm{P}=0.459$ ). For women, the music group noticed an improvement in the pain score (mean change $=-0.14, \mathrm{P}=0.590$ ), while the non-music group significantly worsened (mean change $=1.14, \mathrm{P}=0.008$ ).

Conclusions: Women who listened to music of their choosing experienced significant improvement in overall perceived pain compared to women who did not listen to music. Women may benefit from music as a novel tool to alleviate pain during outpatient clinic urological procedures.

Keywords: Music therapy; women's health; urology clinic procedure

Submitted Oct 05, 2020. Accepted for publication Mar 30, 2021.

doi: $10.21037 /$ tau-20-1311

View this article at: http://dx.doi.org/10.21037/tau-20-1311 


\section{Introduction}

Many urologic procedures done in outpatient clinics are essential to prevent, diagnose, and/or treat a wide variety of diseases and/or problematic symptoms (1). However, barriers to having these procedures done, especially pain, can lead to negative outcomes for patients (2-4). Additionally, pain and anxiety from procedures leads to an increased use of sedation $(5,6)$ and opioid prescriptions (6), both of which come with potential risks and complications. Music therapy is a well-studied treatment that has been shown by various researchers to minimize pain in a number of different procedures $(7,8)$. It can provide distraction while minimizing feelings of pain and the negative emotions associated with uncomfortable experiences (9). Preferred music, in particular, has been theorized to provide a sense of familiarity especially in an unfamiliar clinic or hospital setting. It adds an element of control for patients acting as a coping mechanism that allows patients an independently operated form of analgesia (9).

Several studies have examined music's potential in reducing pain, particularly in urological procedures done in clinics that are not typically performed under anesthesia (10-14). However, many of these studies focused on either a single type of procedure $(8,10,11)$ or specific genre of music, usually classical (12). Differences in response to music based on gender has been investigated by Shim et al., but their focus was specifically on urodynamic studies (13). Although findings from these studies are extremely valuable from several standpoints, it has yet to be investigated whether music can alleviate pain across a variety of outpatient urologic procedures. Additionally, patients being able to select music of their choosing and the effect it has on pain during these procedures has not been studied well. Therefore, we saw that it is necessary to focus on the effects of patients listening to preferred music during a variety of in-clinic urologic procedures. We extrapolated the data gathered beyond just music and non-music groups and also examined differences between genders, as prior studies have shown differences in response between men and women (15). The primary objective of our study is to determine if music can be used as a novel tool for decreasing pain during urological procedures in a clinic setting compared to the current standard of care.

We present the following article in accordance with the CONSORT reporting checklist (available at http://dx.doi. org/10.21037/tau-20-1311).

\section{Methods}

\section{Randomization and music selection}

This was an unblinded, parallel study and single investigator series done in an academic center by Dr. Kellen Choi, an experienced urological surgeon. Prior to data collection, approval from the University of Louisville Institutional Review Board was acquired (IRB Number 18.0394). The study was conducted in accordance with the Declaration of Helsinki (as revised in 2013) and each participant gave informed consent before taking part in the study. Initial exclusion criteria included analgesic use 24 hours prior to the procedure, diagnosis of chronic pelvic pain, or diagnosis of hearing impairment. For this study, a total of 91 male and female patients at an academic outpatient urology clinic participated. Originally, 100 patients were enrolled, however, 9 of them did not complete their consent paperwork, and were therefore excluded from the study. All 91 patients underwent either cystoscopy, cystoscopy with stent pull, or a urodynamic study and were randomized into one of the two groups via coin toss. Sample size was determined to be appropriate after consulting our statistics department, who aided in completing a thorough literature review and based our sample size on previous studies with similar endpoints. There were 53 patients in the music group and 38 in the non-music group. Breakdown of patient distribution is outlined in Figure 1. Those in the music group were allowed to select and listen to music of their choice during their procedure. All procedures were performed in the University of Louisville Physicians Outpatient Center. After patients were consented and randomized to music and non-music groups, patients in the music group were asked to select their preferred song prior to their procedure. The music was started immediately before the procedure began with the patient in appropriate procedural position, and was played on a cellular device throughout their procedure. Patients did not wear headphones and a standard volume level was not used. Patients in the non-music group did not have any music playing throughout their procedures.

\section{Pain measurement}

In order to measure pain level, the Visual Analog Pain Scale (VAPS) which ranged from 0 to 10 was used, with 10 being the highest level of pain a patient can report. Patients 


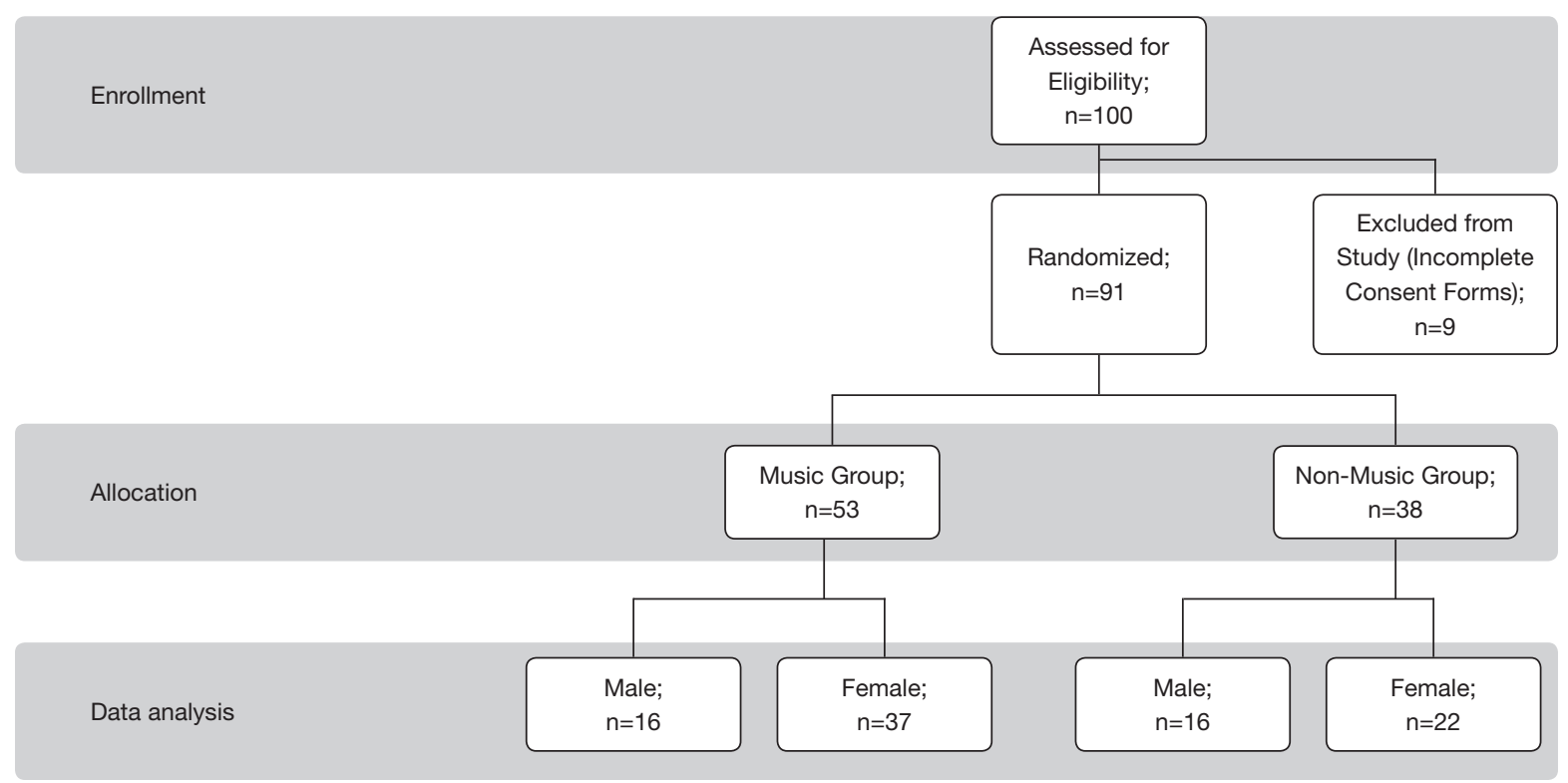

Figure 1 Study flow diagram displaying the enrollment, treatment allocation, and data analysis for groups of patients included in our study.

circled their pain level on the scale before their procedure. Participants were then asked to assess their pain again on the same scale after the completion of their procedure. All patients received local anesthesia in the form of $2 \%$ lidocaine jelly administered immediately prior to their procedure.

\section{Statistical analysis}

Descriptive statistics such as frequencies and percentages, along with means and standard deviations are reported for gender and the pain scale scores by the music or non-music groups. Where appropriate either Pearson's Chi-Square or Independent-Sample $t$-test are used to compare the two study groups. A $2 \times 2 \times 2$ mixed randomized-repeated ANOVA was performed on the VAPS where female and male patients were compared to the music or non-music group before and after the procedure. A similar $2 \times 2 \times 5$ mixed randomized-repeated ANOVA was performed on those randomly assigned to the music group where female and male patients were compared on type of music they listened to and their perceived pain measured before and after the procedure. Statistical significance was set at convention of $\mathrm{P}<0.05$. Data were analyzed using SPSS Version 25 (SPSS, RRID:SCR_002865). Our primary end point was to determine if listening to preferred music could significantly reduce the level of patients' perceived pain and identify if differences in response to therapy existed between genders.

\section{Results}

There was a significant three-way interaction between time (before and after procedure), group (listened to preferred music or did not listen to music), and gender, $\mathrm{F}(1,87)=5.85$, $\mathrm{P}=0.018$. Means and standard deviations for the time $\times$ group $\times$ gender cells are presented in Table 1 . Means and 95\% confident intervals are plotted in Figure 2.

The interaction of time and group differs by gender. Therefore, interactions were compared separately for female and male patients. For female patients, a significant interaction effect existed, $\mathrm{F}(1,57)=8.43, \mathrm{P}=0.005$, so test of simple effects were performed. The test showed a statistically non-significant improvement in the pain score occurred going from before to after procedure in the music group (before mean score $=1.99$; after mean score $=1.85$, $\mathrm{P}=0.615$ ), while the non-music group significantly worsened (before mean score $=2.43$; after mean score $=3.57, \mathrm{P}=0.002$ ). Further, while music did not lead to a statistically significant reduction in pain from before to after procedure within the music group, the reduction in pain in the music group after the procedure was statistically significant when compared to the non-music group (music/after mean score $=1.85$; non- 
Table 1 Mean pain as a function of time, group, and gender

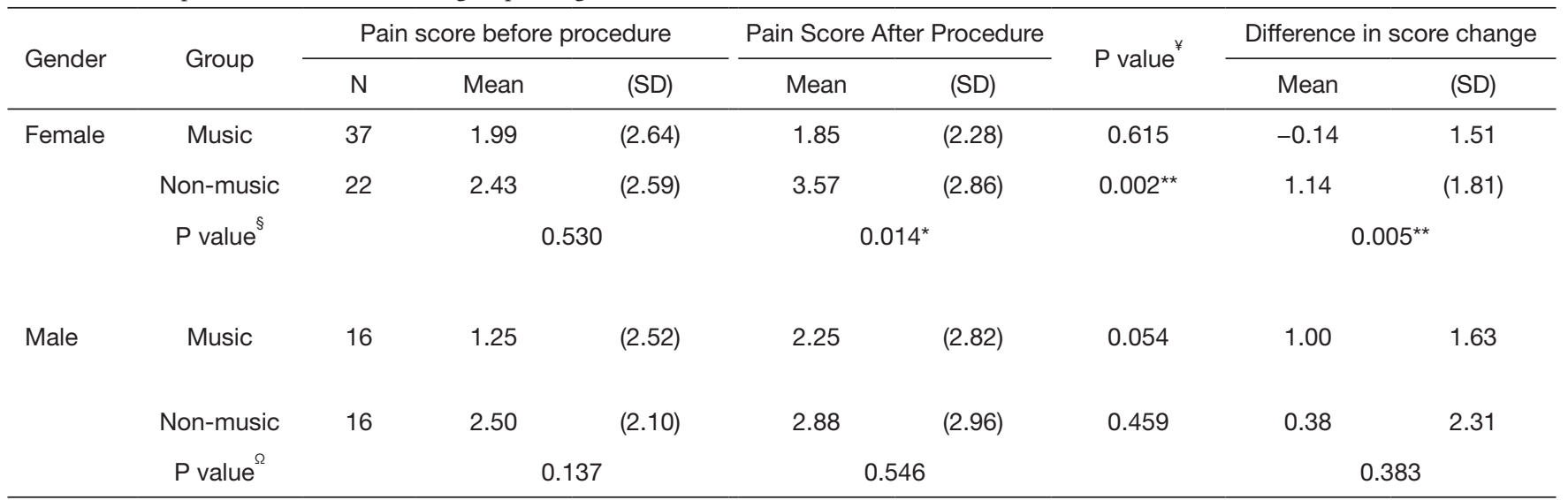

The ${ }^{\S}$ symbol reflects the significance level in no music versus music groups for females on their pre-therapy mean pain score, posttherapy mean pain score and mean change score difference. The ${ }^{\Omega}$ symbol reflects the significance level in no music versus music groups for males on their pre-therapy mean pain score, post-therapy means pain score and mean change score difference. The ${ }^{*}$ symbol reflects the difference in mean scores for each group going from pre-therapy to post-therapy. ${ }^{\star}$ Reflects $\mathrm{P}<0.05$; ${ }^{* *}$ Reflects $\mathrm{P}<0.01$.
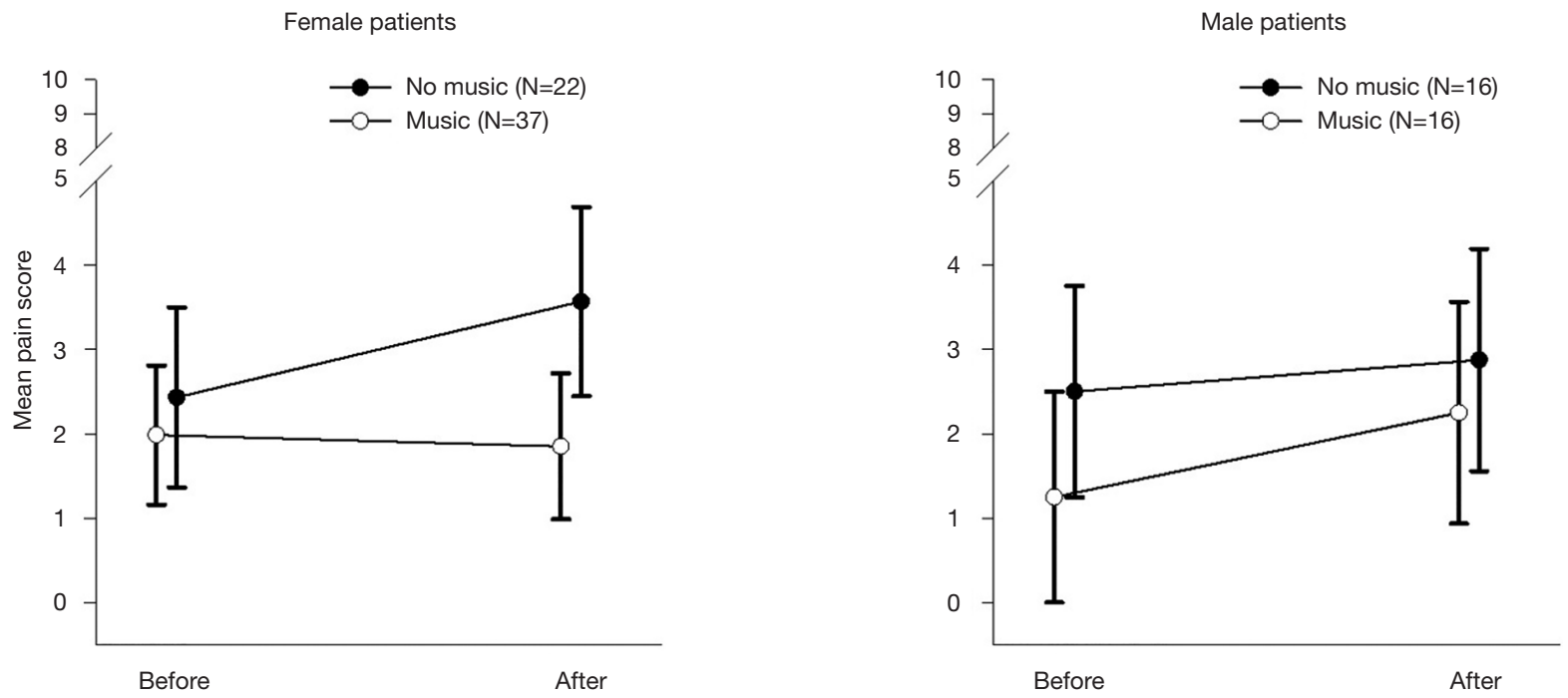

Figure 2 Mean pain as a function of Time, Group, and Gender. Error bars reflect $95 \%$ confident intervals.

music/after mean score $=3.57, \mathrm{P}=0.014)$. The interaction effect shows a difference in the mean change of scores from before to after therapy between the music and non-music group (music change score $=-0.14$; non-music change score $=1.14, \mathrm{P}=0.005)$. It is also important to note that there was not a statistically significant difference between music and non-music groups in pre-procedure pain levels, $\mathrm{P}=0.53$.

No interaction effect for male patients existed as their pain scores worsened clinically in both music (before mean score $=1.25$; after mean score $=2.25, \mathrm{P}=0.054)$ and non- music (before mean score $=2.50$; after mean score $=2.88$, $\mathrm{P}=0.459)$ groups, $\mathrm{F}(1,30)=0.78, \mathrm{P}=0.383$.

For patients randomly assigned to the music group, there was no significant three-way interaction between time (preand post), type of music (rock, classical, pop, Christian, country) and gender, $\mathrm{P}=0.149$. A time $\times$ type of music effect also did not exist, $\mathrm{P}=0.539$, indicating that music genre did not have a statistically significant effect on patient pain scores. None of the participants experienced adverse events or side effects related to the implementation of music. 


\section{Conclusions}

Outpatient clinic urological procedures are necessary for a variety of diagnostic and therapeutic purposes. Many of these procedures are often invasive and embarrassing to patients, involving catheter insertion, filling the bladder with fluid, and voiding on demand all in the presence of medical staff (16). Patients often experience pain, apprehension and other physical burdens from these procedures (16-18). Prior studies on the subject have shown that music can help reduce pain $(8,10-13)$ and increase patients' willingness to undergo a procedure $(7,8)$. These studies established the usefulness of music in an outpatient setting, however, most applied to a specific procedure $(10,11)$ or genre of music $(12)$.

In our study, we combined different aspects from these studies to determine the effect of patients listening to preferred music across a variety of outpatient clinical procedures including cystoscopy, cystoscopy with stent pull, and urodynamic studies. Findings demonstrated that female patients listening to their preferred music choice experienced better outcomes with a significantly lower postprocedure pain score compared to women who did not listen to music. We also found that female patients in the music group experienced a significant improvement in pain levels from pre to post-procedure compared to those who did not listen to music. Music did not seem to affect male patients as both groups experienced increased pain scores and the difference in score change between the two groups was not significant. We found that male patients who listened to music did experience a significant increase in perceived pain from pre-procedure to post-procedure, but the change was not significant when compared to the change the non-music group experienced. Age, type of procedure, and music genre did not have statistically significant influence on perceived pain on pre- and post-procedure evaluations.

Our findings in female patients are consistent with and further support the findings from the meta-analysis done by Kyriakides et al. (8) in that music demonstrated a beneficial effect on pain during various outpatient urological procedures. Our results in male patients differ from the study done by Zhang et al. (10), which concluded that music helped male patients experience less pain and discomfort during flexible cystoscopies. The difference in pain response based on gender is not well established in the literature. A study done by Shim et al. (13) found that preferred music had no effect on pain reduction in both men and women. Our results with male patients were consistent with this finding, while our results with female patients differed from it. This could be attributable to the fact that their study strictly assessed pain during a urodynamic study while ours included a number of different procedures, a majority of which were cystoscopies.

Music as adjuvant therapy to decrease pain has a number of proposed mechanisms. It is thought to provide distraction to reduce emotional response and the feeling of pain (9). It has been shown to decrease negative emotions associated with uncomfortable experiences (19). We assumed that music would help reduce pain for both men and women, as no studies have identified a difference in response between genders, but our results showed otherwise.

Possible explanations for the difference in response to music based on gender could be that men have been shown to experience significantly more pain overall compared to women during urological procedures $(17,20,21)$. However, findings of our study were not consistent with those findings, and there was no significant difference in pain levels between male patients and female patients overall. Music's preferential benefit in female patients could be psychologically related. Joseph Veroff (22) at the University of Michigan outlined and supported the hypothesis that women value the process of obtaining things while men valued the impact. Allowing women to choose their music prior to undergoing a procedure could be interpreted as an improvement in the process of the procedure and increase satisfaction while reducing pain.

In our study, we demonstrated that music of choice is significantly impactful in reducing pain in female patients during outpatient clinic urological procedures. This finding has many implications. Intra-operative pain from invasive procedures leads to an increased use of sedation $(5,23)$, which is associated with a number of dangerous risks and potential complications. Pain also leads to more opioid prescriptions post operatively (10), which leads to overprescribing, a key contributing factor to dependence and abuse (24). Studies involving music and other non-narcotic alternatives have shown that when post-operative pain is well controlled, there is a significant reduction in opioid use in the post-operative period $(25-29)$. Furthermore, decreased pain is associated with a higher patient satisfaction, which leads to better outcomes, stronger adherence to treatment plans, and improved patient relations and loyalty (30).

With the recent increase in volume and usefulness of outpatient urologic procedures over the last 20 years (31), it is becoming more important to address patients' willingness 
to undergo necessary diagnostic and therapeutic operations. Music is a low cost, low risk, noninvasive treatment that we have shown to decrease pain in women during these clinical procedures. It is easy to implement and simple to effectively execute. Offering women the option to listen to their preferred choice of music may reduce the need for operating room utilization/general and MAC anesthesia, decrease the use of post-operative narcotics, and minimize barriers to having important procedures done in the future.

This study had limitations. Although a coin toss was used to randomly assign groups, the distribution of those groups was unequal, which could have affected statistical power. The effect of length of procedure on pain score outcomes was not measured, and could have influenced the data. Because difference in response based on gender was discovered in the data after the study was conducted, we could not optimize our initial study design to better consider gender, such has back randomization according to gender or specific statistical analysis designed for testing gender differences. Our male patient enrollment was also much lower compared to our female patient enrollment. The small sample size of male patients could account for the non-significant difference between music and nonmusic groups. Despite these limitations, our study has made intriguing observations. We recommend offering female patients undergoing outpatient clinic urological procedures an option to listen to music of their choosing as a method to decrease pain and make the procedure more enjoyable.

Future studies could include an enforced music group, in which patients listen to music during their procedure, but not of their choosing. This may help to identify if preferred music is more impactful than music of a predetermined genre on patients' reported pain levels. It may also uncover a potential negative and aggravating effect of enforced music. Future studies should also include a placebo control intervention in the non-music group to avoid overestimating the effect music may have. Additionally, we believe assessing anxiety and examining its relationship to pain in these clinical scenarios should be done if this study is replicated. More broadly, findings from this study could be applied elsewhere, such as a perioperative setting before an operating room procedure.

\section{Clinical impact}

Female patients who listened to music of their choice during outpatient clinic urological procedures experience less pain compared to patients who did not listen to music during their procedure. The use of music in clinical procedures may prevent increased use of analgesics and/ or sedation and increase patients' willingness to undergo urological procedures.

\section{Acknowledgments}

Statistical support was under written by the University of Louisville Office of Graduate Medical Education.

Funding: None.

\section{Footnote}

Reporting Checklist: The authors have completed the CONSORT reporting checklist. Available at http://dx.doi. org/10.21037/tau-20-1311

Data Sharing Statement: Available at http://dx.doi. org/10.21037/tau-20-1311

Conflicts of Interest: All authors have completed the ICMJE uniform disclosure form (available at http://dx.doi. org/10.21037/tau-20-1311). The authors have no conflicts of interest to declare.

Ethical Statement: The authors are accountable for all aspects of the work in ensuring that questions related to the accuracy or integrity of any part of the work are appropriately investigated and resolved. Prior to data collection, approval from the University of Louisville Institutional Review Board was acquired (IRB Number 18.0394). The study was conducted in accordance with the Declaration of Helsinki (as revised in 2013) and each participant gave informed consent before taking part in the study.

Open Access Statement: This is an Open Access article distributed in accordance with the Creative Commons Attribution-NonCommercial-NoDerivs 4.0 International License (CC BY-NC-ND 4.0), which permits the noncommercial replication and distribution of the article with the strict proviso that no changes or edits are made and the original work is properly cited (including links to both the formal publication through the relevant DOI and the license). See: https://creativecommons.org/licenses/by-nc-nd/4.0/.

\section{References}

1. Cystoscopy \& Ureteroscopy." National Institute of 
Diabetes and Digestive and Kidney Diseases, U.S.

Department of Health and Human Services, 1 June 2015. Available online: www.niddk.nih.gov/health-information/ diagnostic-tests/cystoscopy-ureteroscopy

2. Lotan Y, Svatek RS, Sagalowsky AI. Should we screen for bladder cancer in a high-risk population: A cost per lifeyear saved analysis. Cancer 2006;107:982-90.

3. Benway BM, Bhayani SB. Lower urinary tract calculi. In: Wein AJ, Kavoussi LR, Partin AW, Peters CA, editors. Campbell-Walsh urology. 11th ed. Philadelphia: Elsevier, 2016:1291-9.

4. Park JC, Citrin DE, Agarwal PK, et al. Multimodal management of muscle-invasive bladder cancer. Curr Probl Cancer 2014;38:80-108.

5. Calleary JG, Masood J, Van-Mallaerts R, et al. Nitrous oxide inhalation to improve patient acceptance and reduce procedure related pain of flexible cystoscopy for men younger than 55 years. J Urol 2007;178:184-8; discussion 188.

6. Alam A, Gomes T, Zheng H, et al. Long-term analgesic use after low-risk surgery: a retrospective cohort study. Arch Intern Med 2012;172:425-30.

7. Cepda MS, Carr DB, Lau J, et al. Music for pain relief. Cochrane Database Syst Rev 2006;2:CD004843.

8. Kyriakides R, Jones P, Geraghty R, et al. Effect of Music on Outpatient Urological Procedures: A Systematic Review and Meta-Analysis from the European Association of Urology Section of Uro-Technology. J Urol 2018;199:1319-27.

9. Mitchell LA, MacDonald RA, Brodie EE. A comparison of the effects of preferred music, arithmetic and humour on cold pressor pain. Eur J Pain 2006;10:343-51.

10. Zhang ZS, Wang XL, Xu CL, et al. Music reduces panic: an initial study of listening to preferred music improves male patient discomfort and anxiety during flexible cystoscopy. J Endourol 2014;28:739-44.

11. Yeo JK, Cho DY, Oh MM, et al. Listening to music during cystoscopy decreases anxiety, pain, and dissatisfaction in patients: a pilot randomized controlled trial. J Endourol 2013;27:459-62.

12. Raheem OA, Mirheydar HS, Lee HJ, et al. Does Listening to Music During Office-Based Flexible Cystoscopy Decrease Anxiety in Patients: A Prospective Randomized Trial. J Endourol 2015;29:791-6.

13. Shim JS, Chae JY, Kang SG, et al. Can Listening to Music Decrease Pain, Anxiety, and Stress During a Urodynamic Study? A Randomized Prospective Trial Focusing on Gender Differences. Urology 2017;104:59-63.
14. Öztürk E, Hamidi N, Yikilmaz TN, et al. Effect of Listening to Music on Patient Anxiety and Pain Perception during Urodynamic Study: Randomized Controlled Trial. Low Urin Tract Symptoms 2019;11:39-42.

15. Ghaffaripour S, Mahmoudi H, Sahmeddini MA, et al. Music can effectively reduce pain perception in women rather than men. Pak J Med Sci 2013;29:128-131.

16. Scarpero HM, Padmanabhan P, Xue X, et al. Patient perception of video urodynamic testing: a questionnaire based study. J Urol 2005;173:555-9.

17. Yokoyama T, Nozaki K, Nose H, et al. Tolerability and morbidity of urodynamic testing: a questionnaire- based study. Urology 2005;66:74-6.

18. Greenstein A, Bar-Yosef Y, Chen J, et al. Does information provided to men before a urodynamic study affect their expectation of pain? BJU Int 2005;96:1307-9.

19. Lin ST, Yang P, Lai CY, et al. Mental health implications of music: Insight from neuroscientific and clinical studies. Harv Rev Psychiatry 2011;19:34-46.

20. Burke DM, Shackley DC, O'Reilly PH. The community based morbidity of flexible cystoscopy. BJU Int 2002;89:347-9.

21. Ku JH, Kim SW, Kim HH, et al. Patient experience with a urodynamic study: a prospective study in 208 patients. J Urol 2004;171:2307-10.

22. Veroff J. Process vs. Impact in Men's and Women's Achievement Motivation. Psychol Women Q 1977;1:283-93.

23. Kulkarni S, Johnson PC, Kettles S, et al. Music during interventional radiological procedures, effect on sedation, pain and anxiety: a randomised controlled trial. Br J Radiol 2012;85:1059-63.

24. Clarke H, Soneji N, Ko DT, et al. Rates and risk factors for prolonged opioid use after major surgery: population based cohort study. BMJ 2014;348:g1251.

25. Cole LC, LoBiondo-Wood G. Music as an adjuvant therapy in control of pain and symptoms in hospitalized adults: A systematic review. Pain Manag Nurs 2014;15:406-25.

26. Crowe L, Chang A, Fraser J, et al. Systematic review of the effectiveness of nursing interventions in reducing or relieving post-operative pain. Int J Evid Based Healthc (Wiley-Blackwell) 2008;6:396-430.

27. Economidou E, Klimi A, Vivilaki V, et al. Does music reduce postoperative pain? A review. Health Sci J 2012;6:365-77.

28. Hole J, Hirsch M, Ball E, et al. Music as an aid for postoperative recovery in adults: a systematic review and meta-analysis. Lancet 2015;386:1659-71. Erratum in: 
Lancet 2015;386:1630.

29. Poulsen MJ, Coto J. Nursing music protocol and postoperative pain. Pain Manag Nurs 2018;19:172-6.

30. Brokelman RB, Haverkamp D, van Loon C, et al.

The validation of the visual analogue scale for patient

Cite this article as: Anglin C, Knoll P, Mudd B, Ziegler C, Choi K. Music's effect on pain relief during outpatient urological procedures: a single center, randomized control trial focusing on gender differences. Transl Androl Urol 2021;10(6):2332-2339. doi: 10.21037/tau-20-1311 satisfaction after total hip arthroplasty. Eur Orthop Traumatol 2012;3:101-5.

31. Kaye KW. Changing trends in urology practice: increasing outpatient surgery. Aust N Z J Surg 1995;65:31-4. 